\title{
The blast relief sandwich panel fixing under the explosion energy action
}

\author{
Vladimir Rybakov ${ }^{1 *}{ }^{[0000-0002-2299-3096]}$, Olga Gracheva $^{2}$, Mikhail Ogurtsov ${ }^{2}$, Saydiolimkhon \\ Abdusattarhuzha $^{3}$, and Ikbaloy Raimova ${ }^{4}$ \\ ${ }^{1}$ Peter the Great St. Petersburg Polytechnic University, St. Petersburg, Russia \\ ${ }^{2}$ LLC "Stroypanel", St. Petersburg, Russia \\ ${ }^{3}$ LLC "UzLITI Engineering", Tashkent, Uzbekistan \\ ${ }^{4}$ Tashkent Institute of Irrigation and Agricultural Mechanization Engineers, Tashkent, Uzbekistan
}

\begin{abstract}
This article is devoted to the assessment of the efficiency of using wall sandwich panels with mineral wool core, sheathing made of galvanized steel with a polymer coating, used as blast-relief panels. The article presents the developed seating unit for the wall sandwich panel at the moment of the explosion energy influence. As a result of the experiments carried out, when an excess pressure of no more than $3.0 \mathrm{kPa}$ in the room is reached, the safety shut-off devices ensure the discharge of the displaced element, which avoids damage to the main elements of the frame. According to the results of 2 tests, the actual value of the overpressure for opening the displaced element is $2.7 \mathrm{kPa}$, which allows the discharge of the displaced element to be ensured. In the course of the study, the expediency of using blast-relief panels(BRP) in the form of wall sandwich panels was substantiated, and this technical solution was implemented at the facility with the possibility of a deflagration explosion
\end{abstract}

\section{Introduction}

At present, the requirements for ensuring resistance against explosions, for the explosion safety of existing and explosive transport, energy and industrial facilities are significantly tightened. This happened due to the need to ensure an increased level of safety at industrialhazardous facilities to service personnel and technological equipment in case of emergency.

Oil refining facilities and facilities used in the production of explosive substances, chemicals, pipelines, gas stations, thermal power plants, boiler houses, workshops for the preparation and transportation of coal dust, are classified as explosive.

The relevance of the research topic is ensured due to the emerging emergency explosions of gas-air, steam-air, dust-air mixtures at industrial explosive objects for various purposes, as a result of which human casualties and material damage occur.

At the moment, the problem of uncontrolled combustion of gas-air, steam-air, dust-air mixtures is given considerable attention worldwide due to its relevance, since it is associated with great material damage and leads to human casualties.

\footnotetext{
*Corresponding author: fishermanoff@mail.ru
} 
Analysis of accidents in buildings at explosive industries showed that glazing is an effective anti-explosive device. However, in some cases, during explosions inside the premises, despite the fulfilment of regulatory requirements, the destruction of the main structures, particularly the wall fence, occurred. In addition to the destruction of the glazing, there is a complete and partial separation of the sashes from the window spans, and an example is shown in Figure 1.

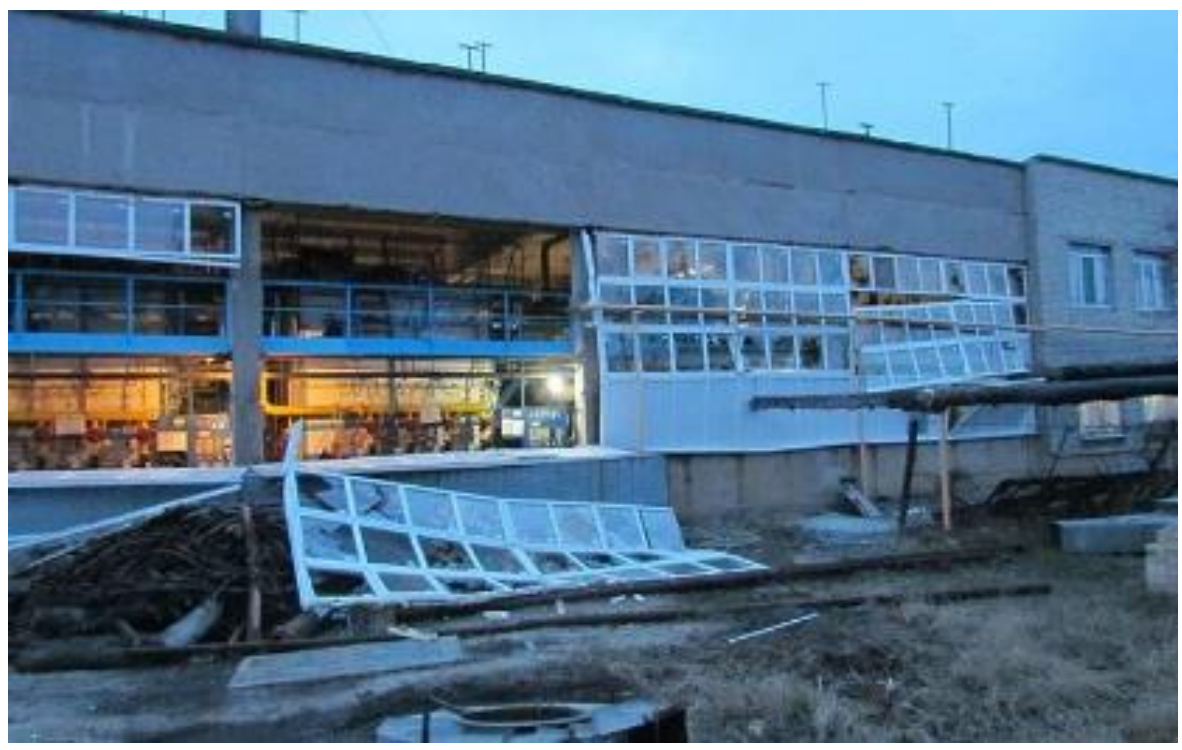

Fig. 1. Separation of bindings from window spans

The bindings threw to the side injure people and damage technological installations and structures of buildings.

For the development of design solutions for the protection of buildings from explosions, it is first necessary to assess the explosiveness of a specific production process located in the building to further establish the magnitude and nature of the loads acting on the enclosing structures when using specific elements of blast-relief panels.

This indicates a need for further development of methods to ensure against explosion resistance of premises, based on the use of blast-relief panels.

To date, the reasons that led to the explosion of combustible mixtures inside the building have been analyzed. Methods for determining the explosive loads perceived by the enclosing structures during an explosion have been developed. A method for establishing the required area of safety structures and an installation method for explosive buildings have been developed. A review of domestic regulatory literature showed the absence of documents that would allow for the calculation of sandwich panels. The only exceptions are recommendations [1], which are optional. They do not take into account all variants of fracture mechanisms, particularly, shear fracture, compression of the middle layer, shear strength under long-term loading. [2, 4, 12, 13]

However, in the scientific literature, one can find works devoted to the search for an optimal calculation method for both a sandwich panel and the nodes of their interface with other structural elements. For example, O.A. Tusnina described in her works $[5,6,7]$ the method of calculating the conjugation of a Z-shaped run with a sandwich panel. Mircea Georgescu [8] and Marcin Kujawa [9] are doing the same research on this issue. Kahina Sad Saoud $[10,11]$ solves the problem of loss of stability in compressed skins. 
Baryshev G.K. [14] devotes a new general experimental method for studying the anisotropy of conducting materials of various functional purposes. The difference between the presented method and the previously known one is in the high rate of anisotropy assessment, ensuring the possibility of anisotropy assessment of the properties of materials by the volume of the sample or product under investigation during their manufacture or operation. The procedure for measuring the anisotropy of electrophysical properties and the results of the study of some samples are presented.

Vedishcheva I.S. [15] presents numerical research results to the influence of heat conducting inclusions on thermo-technical properties of vertical and horizontal sandwich panels. The numerical analysis is carried out using software ANSYS. Based on the numerical analysis results, the regression equations for calculating minimal values of temperature on an internal surface of a vertical sandwich panel are easy to obtain. The analysis of the thermal field of the "sandwich panel - metal frame" [16-18] system shown that the hygiene requirements do not comply. The proposed solution allows the reduction of the influence of heat conducting inclusions on thermo-technical properties.

Premises of categories A and B for explosion and fire hazard, by the set of rules SP 4.13130.2013 "Limiting the spread of fire on protection objects", should be equipped with external blast-relief panels (BRP).

According to the Recommendations for the calculation of parameters of easily resettable structures for explosive and fire hazardous premises of industrial facilities. VNIIPO, 2015 wall panels can be used as displaced BRP.

Blast-relief displaceable panels based on three-layer wall panels for civil and industrial buildings (hereinafter - BRPP, blast-relief panels based on three-layer wall panels), performing the function of anti-explosion safety structures, designed to reduce the excess pressure arising from internal explosions of steam-gas-dust-air combustible mixtures in buildings and structures.

The principle of operation of the BRPP is as follows - when the overpressure from the explosion is applied to the enclosing structures, the safety shut-off devices that secure the BRP panels are destroyed, they are displaced outside the building, and the pressure is released. The panels are protected from scattering by safety cables, by which they are fixed to supporting structures. Each BRP panel is attached to the supporting structures with at least two safety cables. Blast-relief panels are designed for response pressure depending on the category of the room, as well as wind and operational loads.

For industrial buildings, following SP 56.13330.2011 «Industrial buildings», the area of blast-relief panels should be determined by calculation. In the absence of design data, the area of blast-relief panels should be at least $0.05 \mathrm{~m}^{2}$ per $1 \mathrm{~m}^{3}$ of the volume of a room of category A and at least $0.03 \mathrm{~m}^{2}$ for rooms of category $\mathrm{B}$.

The actuation pressure should be in the range of 2.0 to $3.85 \mathrm{kPa}$ and not less than 3.5 wind pressure plus the pressure required to displace the BRP. Each BRP panel must be fixed with at least four safety locking devices (SLD). The operating load of the SLD is selected individually for each project and is in the range of $0.5-2.0 \mathrm{kN}$.

The object of the research is the seating units of blast-relief panels made of sandwich panels.

The subject is the destruction of units from the impact on the wall sandwich panel of the force of the overpressure of the explosion with its displacement outward without using an additional source of energy.

The aim of the work is to develop and justify the attachment points for wall sandwich panels under the influence of air-gas mixtures.

The following tasks were solved:

1.development of assemblies for easily dumped structures made of sandwich panels under the influence of explosion energy; 
2.testing with a wall sandwich panel under the influence of explosion energy;

3.implementation of the proposed technical solution at the facility with the possibility of a deflagration explosion.

\section{Materials and Methods}

The panel was manufactured on 03/06/2019 on an automatic flow line with dimensions of $1550 \cdot 1200 \mathrm{~mm}$ with a mineral wool core with a thickness of $200 \mathrm{~mm}$, with a sheathing of galvanized steel with a Polyester polymer coating.

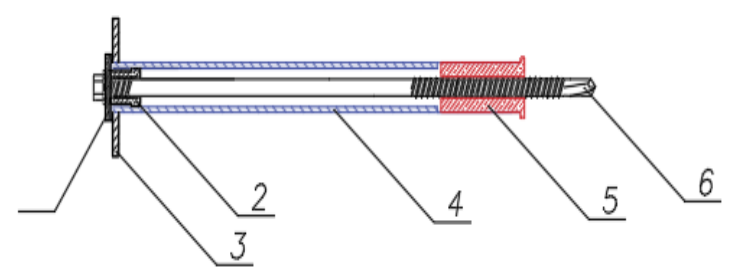

Fig. 2. Structure of destructive fasteners BRP

Figure 2 shows a knot of destructible fasteners for blast-relief panels made of a sandwich panel with the main components of this structure.

1. Destructive washer of BRP, 2. Centering sleeve, 3. Reinforcing metal washer, 4. Metal sleeve, 5. Centering sleeve, 6. Self-cutting screw, 7. Reinforcing sleeve, 9. Bracket, 10. Safety rope, 11. Selftapping screw 5.5·32, 12. BRP sandwich panel, 13. Reinforcing washer, 14. M8 washer, 15. Grover washer, 16. M8 nut, 17. Stud M8

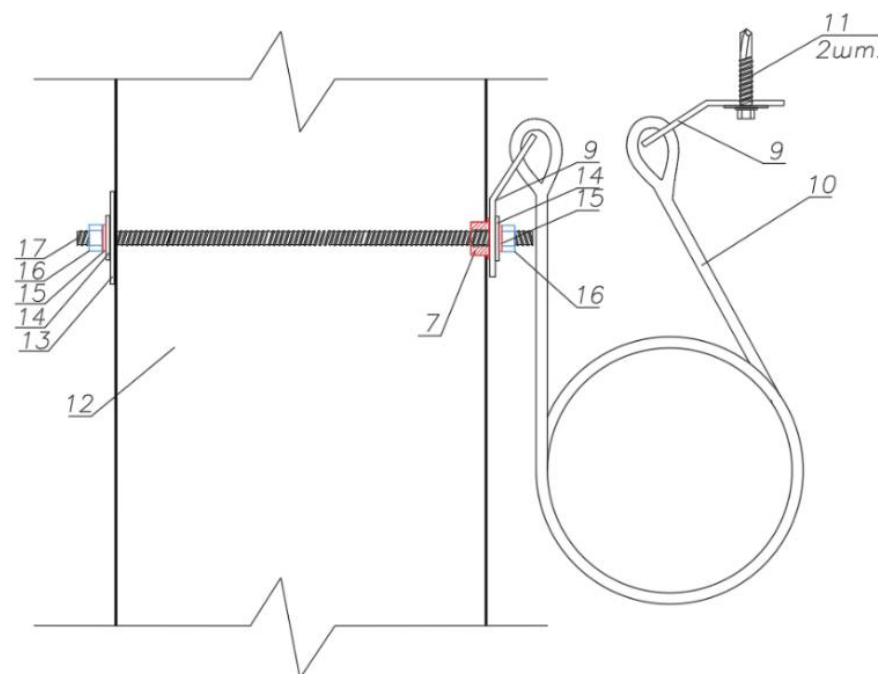

Fig. 3. The safety substructure

Figure 3 also shows the safety substructure, the components of which are a reinforcing sleeve, a bracket, a safety cable, a $5.5 \cdot 32$ self-tapping screw, an easy-to-release sandwich panel, a reinforcing washer, an M8 washer, a grover washer, an M8 nut and an M8 threaded stud with a length corresponding for the thickness of the sandwich panel. 
The test specimen is a displaceable BRP in the form of a three-layer wall metal panel with dimensions $(1550 \cdot 1200) \mathrm{mm}$ filled with mineral wool $200 \mathrm{~mm}$ thick (Figure 4), installed in the discharge opening, fixed to the opening with the help of safety locking devices, manufactured according to TU 25.11.23-004-65536585-2019 «Structures (curtain walls) made of three-layer metal panels with mineral wool insulation». According to the requirements of MI-001.01.06.2017 "Test procedure for blast-relief panels " [18], two BRP samples were tested.

The general view of the structure is shown in the figure 4. The principle of operation of this BRP is based on the destruction of nodes from the impact on the wall panel of the force of the overpressure of the explosion with its displacement outward without using an additional source of energy.

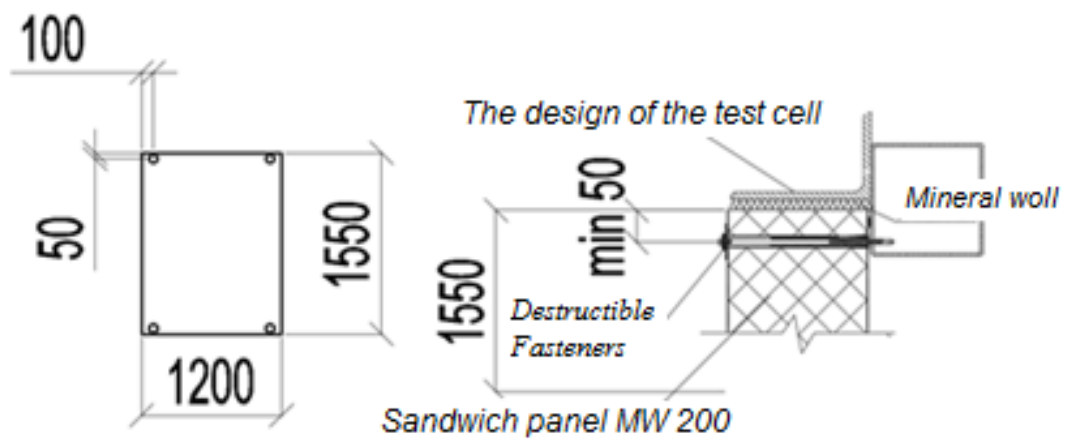

Fig. 4. The general view of the structure.

The test of the presented sample was carried out under the following environmental parameters:

- ambient temperature $-6.0^{\circ} \mathrm{C}$;

- atmospheric pressure $-100.2 \mathrm{k \Pi a}$;

- relative humidity $-59 \%$.

After mounting the sample, the amount of combustible gas required to create a stoichiometric concentration was supplied to the explosion chamber. Concentration control was carried out using a gas analyzer. After the formation of the required concentration of the gas-air mixture in the explosion chamber, the gas supply was stopped.

No later than $30 \mathrm{~s}$. after stopping the gas supply, the gas-air mixture was ignited.

During the test, following the requirements of clause 7.5 of GOST R 56289-2014 [19], the following were registered:

- change of overpressure in time inside the explosion chamber using overpressure sensors;

- the process of releasing the discharge hole of the explosive chamber from the displaceable element of the BRP;

- the nature of the destruction of the sample.

Following the requirements of clause 7.6 of GOST R 56289-2014 [19], the procedure for determining the overpressure for opening the BRP:

- analysis of video footage of the high-speed shooting, which determines the time elapsed from the moment of ignition of the gas-air mixture inside the explosion chamber to the beginning of opening the discharge opening

- analysis of the graph showing the dependence of overpressure on time inside the explosion chamber, according to which the overpressure of opening the BRP is determined, corresponding to the start time of opening the relief opening, set by video footage. 
Testing of samples of displaceable BRPs made of sandwich panels with a safety shut-off device of the SLD type, manufactured following TU 25.11.23-004-65536585-2019 «Structures (curtain walls) made of three-layer metal panels with mineral wool insulation», confirms the possibility of clearing the outlet opening of the building as a result of excessive pressure due to internal deflagration explosion of the gas-air mixture.

Safety shut-off devices must ensure the discharge of the displaced element, which will avoid damage to the main elements of the frame when an overpressure of no more than 3.0 $\mathrm{kPa}$ in the room is reached. According to the results of 2 tests, the actual value of the overpressure for opening the displaced element is $-\Delta p_{o p}=2.7 \mathrm{kPa}$, which allows the discharge of the displaced element to be ensured.

\section{Results}

Testing of samples of displaceable easily ejected structures made of sandwich panels with a safety shut-off device of the SLD type, manufactured following TU 25.11.23-00465536585-2019 «Structures (curtain walls) made of three-layer metal panels with mineral wool insulation», confirms the possibility of clearing the discharge opening of a building as a result of exposure to excess pressure due to an internal deflagration explosion of a gas vapor-air mixture.

The test results are shown in Table 1.

Table 1. Test results of the BRP

\begin{tabular}{|c|c|c|c|c|}
\hline \multirow{2}{*}{ № } & \multirow{2}{*}{$\begin{array}{l}\text { Item on a } \\
\text { RD }\end{array}$} & \multirow{2}{*}{ Name of the parameter } & \multicolumn{2}{|c|}{ Parameter value } \\
\hline & & & Stated & Actual \\
\hline 1 & 2 & 3 & 4 & 5 \\
\hline 1 & $\begin{array}{c}\text { c. } 5.1 .2 \\
\text { GOST R } \\
56288-2014\end{array}$ & $\begin{array}{l}\text { Blast relief panels must have safety } \\
\text { locking devices in the form of latches, } \\
\text { destructible fastening elements or other } \\
\text { structures that release the swing leaf or } \\
\text { a displaced element when it is subjected } \\
\text { to excessive pressure of a certain value. }\end{array}$ & Match & Match \\
\hline 2 & $\begin{array}{c}\text { c. } 5.1 .2 .5 \\
\text { GOST R } \\
56288-2014\end{array}$ & $\begin{array}{l}\text { Safety shut-off devices of the displaced } \\
\text { easily removable design must ensure } \\
\text { complete release of the discharge } \\
\text { opening from the displaced element. }\end{array}$ & Match & Match \\
\hline 3 & $\begin{array}{c}\text { c. 5.1.2.6 } \\
\text { GOST R } \\
56288-2014\end{array}$ & $\begin{array}{l}\text { Safety locking devices for opening the } \\
\text { swing leaf or the displaced element } \\
\text { must use the energy of an emergency } \\
\text { explosion of a gas-air combustible } \\
\text { mixture and do not require the use of an } \\
\text { additional energy source. }\end{array}$ & Match & Match \\
\hline 4 & $\begin{array}{l}\text { c. } 8.2 \text { GOST } \\
\text { R } 56289- \\
2014 \\
\text { c. } 8.12 \\
\text { GOST R } \\
\text { 56288-2014 } \\
\end{array}$ & $\begin{array}{l}\text { Ensuring safe operation of safety shut- } \\
\text { off devices. }\end{array}$ & Match & Match \\
\hline 5 & $\begin{array}{l}\text { c. } 6 \text { TU } \\
25.11 .23- \\
004- \\
65536585- \\
2019\end{array}$ & $\begin{array}{l}\text { Safety shut-off devices must ensure that } \\
\text { the displaced element is discharged } \\
\text { when the room reaches an excess } \\
\text { pressure of } 3.0 \mathrm{kPa} \text {. }\end{array}$ & $\begin{array}{l}\text { The opening } \\
\text { pressure does } \\
\text { not exceed } 3,0 \\
\mathrm{kPa}\end{array}$ & $\begin{array}{l}\text { The opening } \\
\text { pressure composed - } \\
\Delta p_{o p .}=2,7 \mathrm{kPa} \text { (max } \\
\text { value based on the } \\
\text { results of } 2 \text { tests) }\end{array}$ \\
\hline
\end{tabular}




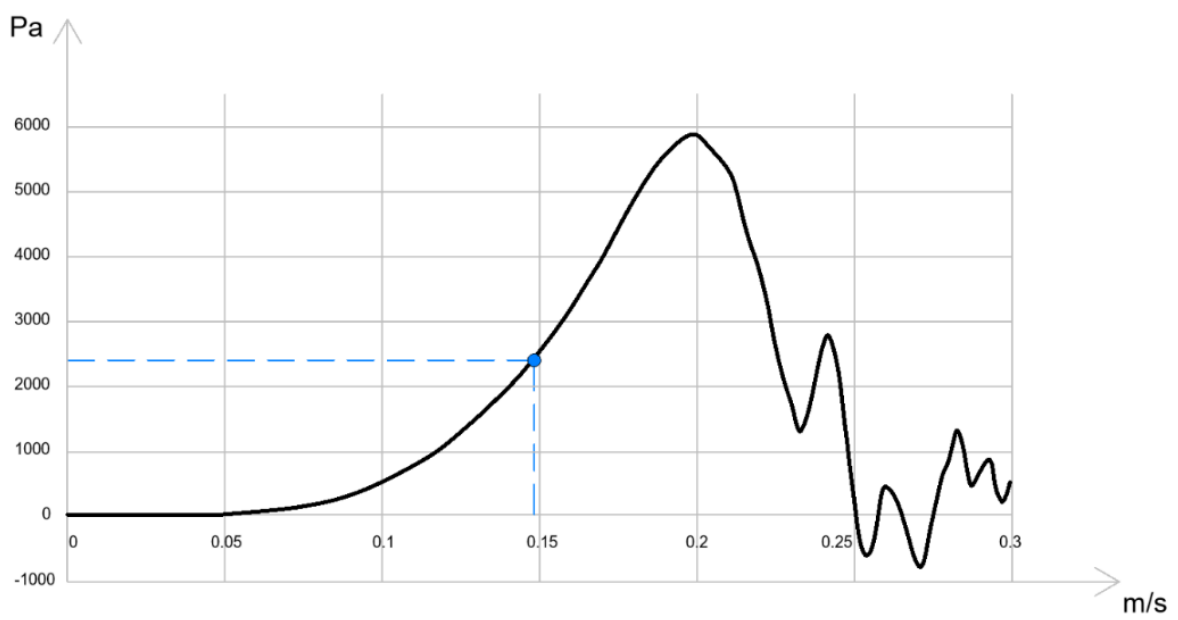

Fig. 5. Pressure change in the chamber volume during testing of the BRP sample №1

Safety shut-off devices must ensure the discharge of the displaced element, which will avoid damage to the main elements of the frame when an overpressure of no more than 3.0 $\mathrm{kPa}$ in the room is reached. According to the results of 2 tests, the actual value of the overpressure for opening the displaced element is $-\Delta p_{o p}=2.7 \mathrm{kPa}$, which allows the discharge of the displaced element to be ensured.

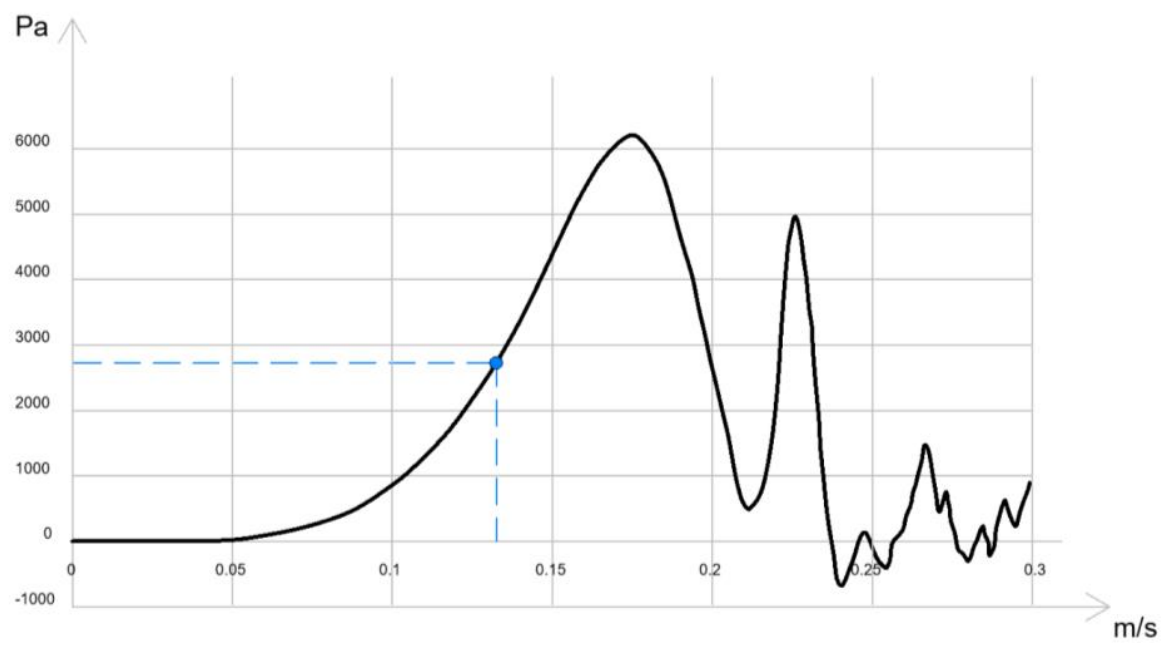

Fig. 6. Pressure change in the chamber volume during testing of the BRP sample №2 


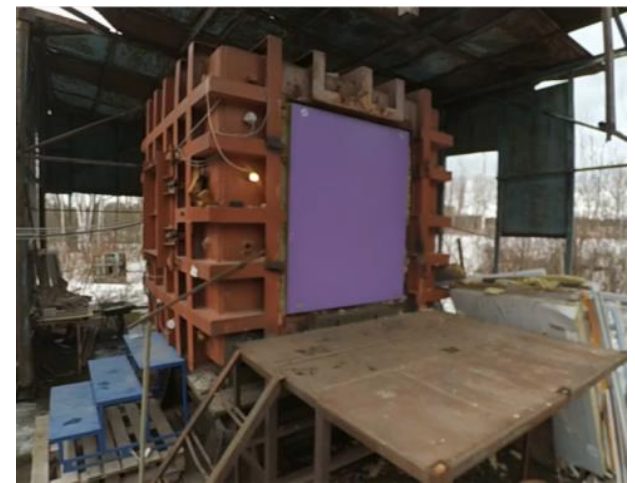

a)

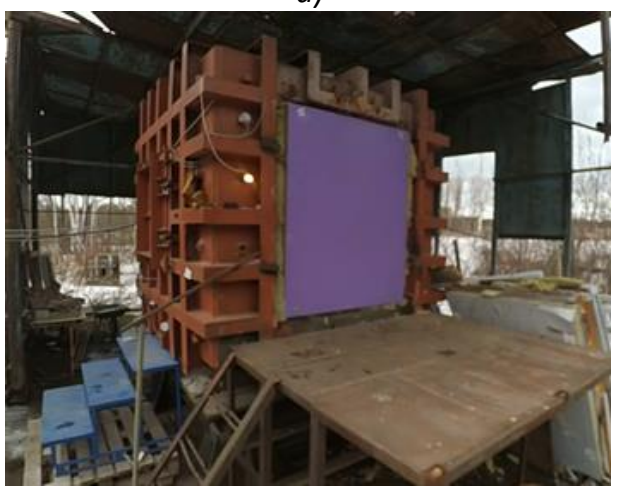

c)

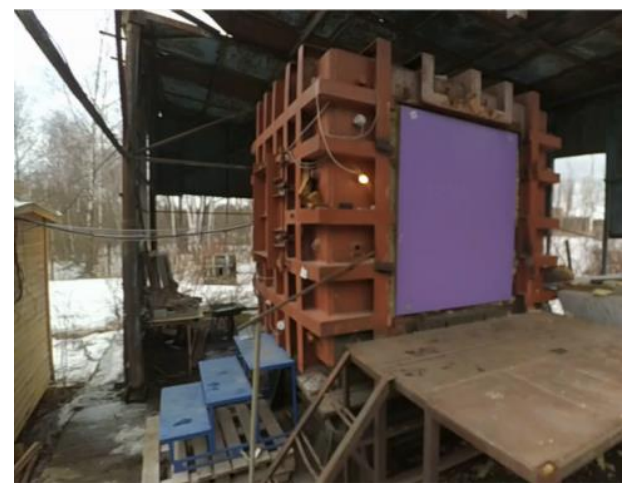

b)

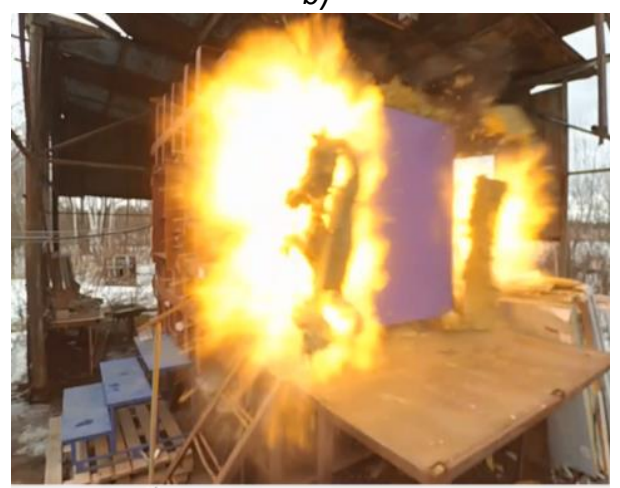

d)

Fig. 7. Stages of the tests: (a) the time of initiation of explosive combustion $(1 \mathrm{~m} / \mathrm{c})$; (b) the beginning of the opening BRP $(148 \mathrm{~m} / \mathrm{c})$; (c) release of the discharge opening from BRP $(200 \mathrm{~m} / \mathrm{c}) ;$ (d) complete release of the discharge opening, burning out of the gas-air mixture inside the blast chamber $(231 \mathrm{~m} / \mathrm{c})$

\section{Discussions}

The resettable BRP of explosive rooms is known according to patent № 119780 dated 04/27/2012, publ. 27.08.2012 (author-holder VL Stilba, class MPKE04N9 / 00).

This resettable BRP for explosive areas contains a wall panel, a resettable blast relief sandwich panel connected to the building frame using support brackets made of a corner metal profile through destructible attachment points. Each bracket has a groove in the places where the parts of the destructible seating unit are installed.

Each destructible seating unit contains a base sleeve, which is located inside the hole of a blast relief sandwich panel, and a destructible attachment element connected to the base sleeve using a pin and a spacer sleeve mounted on the said pin. The spacer sleeve is made with an annular protrusion and is installed with the possibility of excluding the occurrence of contact between the stud and the bracket, the spacer sleeves are made of caprolon, and fluoroplastic discs with a calibrated thickness are used as destructible elements, fixed on the studs by means of a threaded connection.

The technical result provided by this utility model under US Pat. No. 119780, consists of increasing the structure's efficiency as a whole with different pressure fluctuations inside the room, the reliability of the structure at normal pressure, and improving the performance. 


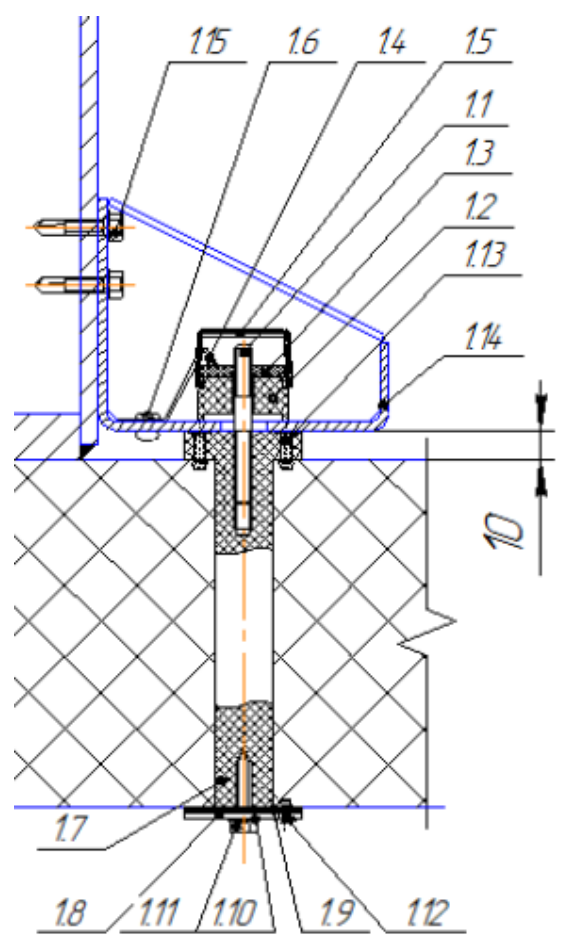

Fig. 8. Seating unit

1.1 Stud, 1.2 Spacer sleeve, 1.3 Destructive element, 1.4 Spring retainer, 1.5 Protective cap,

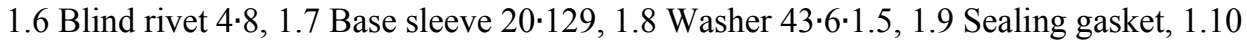
Lock washer 6 stainless steel. steel A2, 1.11 Self-tapping screw 5,5·25, 1.12 Blind rivet 4.10 stainless steel. 1.13 Blind rivet $4 \cdot 18,1.14$ Bracket K-2, 1.15 Self-cut roofing $5.5 \cdot 25$ into metal

The disadvantage of this technical solution is as follows. The technical solution lies in the fact that a special support bracket made of a corner metal profile is attached to the building frame, to which the sandwich panel is attached by means of a destructible seating unit. To do this, it is necessary to drill holes in the sandwich panel for the grooves on this bracket, and this does not happen in the factory but directly during the installation of the panel at the construction site so that the holes in the panel coincide with the grooves of the bracket previously fixed on the building frame. To do this, the sandwich panel should be lifted to the appropriate floor, the holes should be marked for the corresponding grooves, then the panel must be lowered, after the corresponding holes need to be drilled, and after the panel raised again for fastening. That means that the process of mounting the panel is complicated. Also, for the installation of such a structure, two workers are required - from the outside of the panel and the inside, since the destructible fastener is fixed simultaneously both from the outside with the appropriate fastener and from the inside by the destructible unit onto the support bracket. Also, the destructible attachment point of this design, consisting of a destructible element, a spacer sleeve and a stud, must be mounted inside the support bracket, which is a metal trihedron, which significantly complicates the installation process, since it is possible to get to the place of attachment inside such a bracket is difficult enough. 


\section{Conclusions}

The study results contribute to the existing knowledge of the efficiency of using wall sandwich panels with mineral wool core, sheathing made of galvanized steel with a Polyester polymer coating, used as blast-relief panels.

The main results are:

- safety shut-off devices, when an overpressure of no more than $3.0 \mathrm{kPa}$ in the room is reached, must ensure the discharge of the displaced element, which will avoid damage to the main elements of the frame;

- according to the results of 2 tests, the actual value of the overpressure for opening the displaced element is $-\Delta p_{o p}=2.7 \mathrm{kPa}$, which allows the discharge of the displaced element to be ensured.

\section{Acknowledgements}

Acknowledgment is expressed Andrey V. Artemenko, CEO LLC«STROYPANEL» for structure specimens, provided for tests.

\section{References}

1. Of The Russian Federation. Laws. Technical regulations on fire safety requirements (as amended on July 29, 2017) (version effective from July 31, 2018): Federal law No. 123-FZ: [adopted by the state Duma on July 4, 2008: approved by the Federation Council on July 11, 2008], Moscow :JSC "Codex", p. 12, (2012)

2. Recommendations for determining the bearing capacity of roofing and FA-garden sandwich panels of piecemeal Assembly / ed. by N. I. Presnyakov, NII im. Melnikova, Moscow: Metallprofil, p. 44, (2013)

3. Zhmarin E. V. Technology of the future - construction of lightweight buildings and structures with the use of thermal profiles and light beams, /E.V. Zhmarin. - M.: Stroyprofil, No. 5-04, - p. 25, (2004)

4. Mushinsky A., Zimin S. Construction of prefabricated buildings and structures. Construction of unique buildings and structures, № 4(31), pp. 182-193, (2015)

5. Romashko V. Collapsible, prefabricated, building modules, Youth and science: Collection of materials of the VII all-Russian scientific and technical conference of students, postgraduates and young scientists, dedicated to the 50th anniversary of the first human flight into space.- Krasnoyarsk: Siberian Federal University, pp.121-125, (2011)

6. Tusnina O., Heinisuo M. Method of calculating thin-walled bent horns based on EUROCODE, Proceedings of the Moscow state University of civil engineering, № 11, pp. 67-70, (2012)

7. Tusnina O., Danilov A. Experimental and theoretical studies of the VAT run of sandwich panel coating, Vestnik MGSU, pp. 23-36, (2014)

8. Tusnina O.A. load-Bearing capacity of thin-walled cold-formed coating runs taking into account the influence of the stiffness of the connection with sandwich panels, Vestnik MGSU.pp. 73-76. (2014)

9. Georgescu M., Ungureanu V. Stabilization of construction Z-purlins by sandwich panels Full scale xperimental approach, Thin-Walled Structures, pp. 242-249, (2014)

10. Kujawa M., Szymczak C. Numerical and experimental investigation of rotational stiffness of zed-purlins connection with sandwich panels, Thin-Walled Structures, pp. 43-52, (2014) 
11. Sad Saoud K., Le Grognec P. A unified formulation for the biaxial local and global buckling analysis of sandwich panels, Thin-Walled Stuctures, pp. 13-23, (2014)

12. Gosowski B., Gosowski M. Exact solution of bending problem for continuous sandwich panels with profiled facings, Journal of Constructional Steel Research, pp. 53-60, (2014)

13. Gorshkov A., Vatin N., Nemova D., Shabaldin A., Melnikova L., Kirill P. Using lifecycle analysis to assess energy savings delivered by building insulation, Procedia Engineering, № 117, pp.1080-1089, (2015)

14. Baryshev, G.K., Barzov, A.A., Biryukov, A.P., Kondrateva, A.S., Tutnov, I.A. General experimental method of research of anisotropy of conductive materials Key Engineering Materials, 822, pp. 72-78, (2019)

15. Vedishcheva I.S., Ananin M.Y., Al Ali M., Vatin N.I. Influence of heat conducting inclusions on reliability of the system "sandwich panel -metal frame" Magazine of Civil Engineering, 78 (2), pp. 116-127, (2018)

16. Sergeev, V.V., Petrichenko M.R., Nemova D.V., Nefedova A.V., Borodinecs A.B. The building extension with energy efficiency light-weight building walls Magazine of Civil Engineering, 84(8), pp. 67-74, (2018)

17. Shibaeva G., Ibe E., Portnyagin D., Afanasyeva E. Thermal protection of buildings from sandwich panels for Southern Siberia conditions, IOP Conference Series: Materials Science and Engineering, Vol. 597, Is 1, pp. 120-136, (2019)

18. Soden P. Indentation of composite sandwich beams. J. Strain Analysis, № 31, pp. 353360, (1996)

19. Dolganina N.Yu., Sapozhnikov S.B. Characterization of low velocity local impact of sandwich panels. PNRPU Mechanics Bulletin. № 4, pp. 271-282, (2014)

20. Russian Stat Standard GOST R 56288-2014 Window structures with double-glazed Windows that can be easily thrown away for buildings. Moscow: Standartinform, p. 24, (2015)

21. Gumerova E., Gamayunova O., Meshcheryakova T. Energy efficiency upgrading of enclosing structures of mass housing of the Soviet Union// Advances in Intelligent Systems and Computing. 692, pp.432-439, (2018) 